\title{
Morphometric analysis of blood vessels in synovial membranes obtained from clinically affected and unaffected knee joints of patients with rheumatoid arthritis
}

\author{
O FitzGerald, Muriel Soden, Ghada Yanni, R Robinson, B Bresnihan
}

\begin{abstract}
Synovial tissues from inflamed and noninflamed knee joints of 13 patients with untreated rheumatoid arthritis were examined for vascular proliferation and morphological alteration of endothelial cells. Perivascular mononuclear cell infiltration and increased thickness of the synovial lining layer were noted in tissues from inflamed and noninflamed joints of patients with rheumatoid arthritis; vascular proliferation and morphological alteration of endothelial cells to resemble high endothelial venules were seen only in tissues from inflamed joints of patients with rheumatoid arthritis. These observations suggest that the migration of mononuclear cells from the peripheral blood to the perivascular areas and lining layer occurs before vascular proliferation and morphological alteration of endothelial cells.
\end{abstract}

The histological features which characterise established synovitis in patients with rheumatoid arthritis are well established. ${ }^{1}$ They include thickening of the lining layer; a variable degree of mononuclear cell infiltration, which consists predominantly of lymphocytes, macrophages, and plasma cells; fibrin deposition; and proliferation of the postcapillary venules and capillaries in the sublining layer. Vascular proliferation may determine the rate of disease progression in rheumatoid arthritis. ${ }^{2}$ Similar angiogenic effects have been described in patients with diabetic retinopathy ${ }^{3}$ and neoplasia. ${ }^{4}$

Several studies have examined the relation between changes in the synovial vascular endothelium and lymphocyte infiltration. ${ }^{5-7}$ Interest has been generated by the structural and functional similarities found in normal lymphoid tissues and rheumatoid synovial membranes. In normal lymphoid tissues lymphocytes migrate through postcapillary venules lined by tall endothelial cells. ${ }^{8-11}$ These venules are termed high endothelial venules. Lymphocytes in the rheumatoid synovium also migrate from the blood through postcapillary venules similar to high endothelial venules to form characteristic lymphocyte-rich perivascular infiltrates. ${ }^{67}$ There is considerable evidence suggesting that the unique morphology of endothelial cells lining high endothelial venules is lymphocyte dependent. ${ }^{5}{ }^{10-15}$ In the rheumatoid synovium it has been shown that the tallness of endothelial cells is strongly correlated with the number and percentage of perivascular lymphocytes. ${ }^{6}$ Local factors other than those related to circulating lymphocytes must also be operating in rheuma- toid arthritis, however, as many joints may not be affected. The aim of this study was to compare indices of vascular proliferation and endothelial cell 'tallness' in synovial membrane biopsy specimens obtained from clinically inflamed and from unaffected knee joints of patients with rheumatoid arthritis. Vascular proliferation and an increase in endothelial cell tallness was observed only when overt synovitis was present. An increase in the thickness of the lining layer and lymphocyte infiltration was apparent in some patients before vascular endothelial change.

\section{Patients and methods}

PATIENTS AND CONTROLS

As part of a previous study ${ }^{16}$ a number of patients first presenting with untreated classical or definite rheumatoid arthritis ${ }^{17}$ to the Department of Rheumatology, St Vincent's Hospital, Dublin, Ireland, underwent synovial needle biopsy of one knee joint. Approval had been obtained from the St Vincent's Hospital ethics committee. Sufficient tissue for further study was available from nine biopsy specimens obtained from patients with clinically overt knee joint synovitis (group A) and from four specimens obtained from patients with apparently unaffected knee joints (group B). None of the patients in either group had ever received gold salts, antimalarial compounds, D-penicillamine, or corticosteroid treatment; patients who had received intra-articular corticosteroid injections were excluded from the study. Thirteen controls matched for age were chosen from subjects undergoing postmortem examination (group C). All control subjects had apparently normal knee joints and a review of their case notes excluded a history of arthritis.

\section{SYNOVIAL BIOPSY}

After informed consent, blind needle biopsy of one knee joint was performed using a Williamson Holt synovial biopsy needle (Shrimpton and Fletcher Needle Industries, Redditch, UK) as described previously. ${ }^{16}$ Samples were fixed in formalin for embedding in paraffin and evaluation. Samples from the necropsy controls were obtained by open exposure of the knee joint within 12 hours of death from the medial, lateral, and suprapatellar recesses.

SYNOVIAL HISTOLOGY

Formalin fixed samples were sectioned to $7 \mu \mathrm{m}$ thickness and stained with haematoxylin and eosin. Sections were also stained with peroxidase 


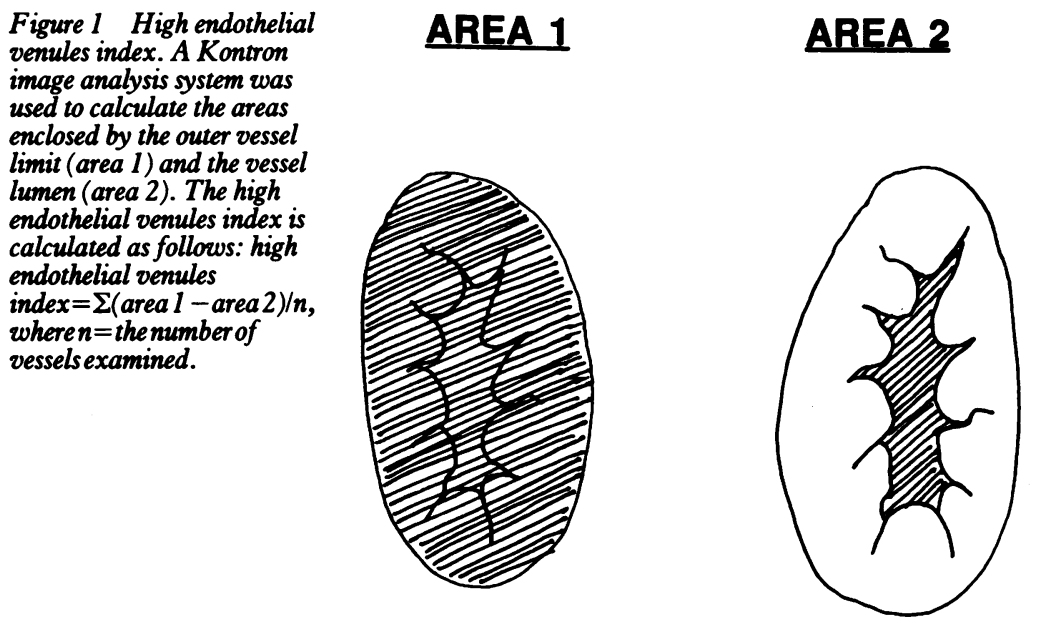

HEV - Index $=\frac{\sum \text { (Area 1 }- \text { Area 2) }}{n}$
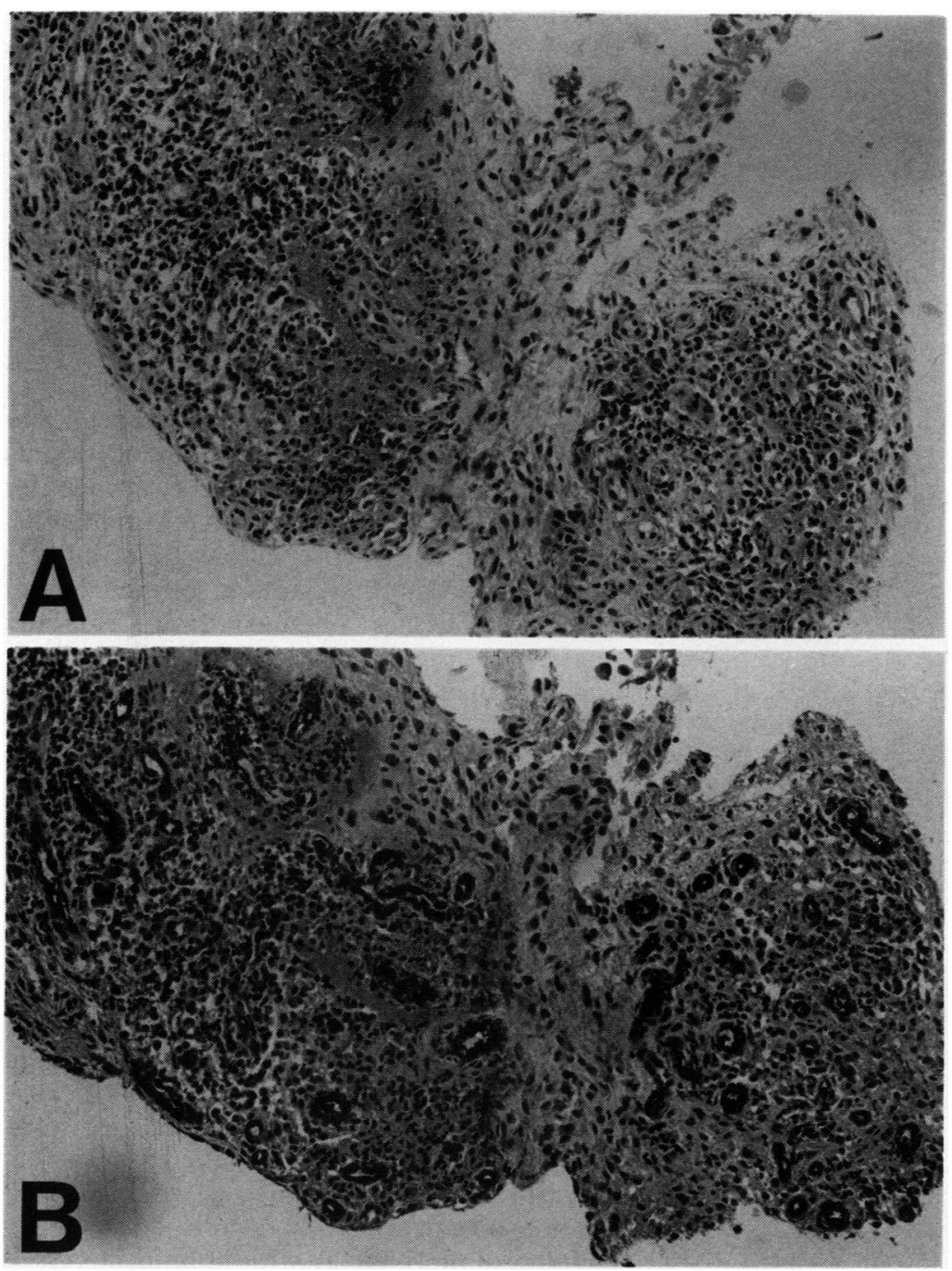

Figure 2 Synovial tissue obtained from a clinically affected rheumatoid arthritis knee joint stained with $(A)$ haematoxylin and eosin and $(B)$ anti-factor $V I I I$ related antigen. digesting with $0.1 \%$ trypsin in $0.1 \%$ calcium chloride at $37^{\circ} \mathrm{C}, \mathrm{pH} 7 \cdot 8$, for 15 minutes. Extensive washing with water and TRIS buffered saline removed the trypsin, and the tissues were then incubated for 10 minutes in normal swine serum (diluted 1:5 in TRIS buffer) before incubation for one hour in antiFVIII RAg (diluted 1:400 in TRIS buffer). Successive incubations and wash cycles followed with swine anti-biotinylated rabbit IgG (Dako Laboratories, Copenhagen, Denmark) for 30 minutes, avidin biotin complex (Dako Laboratories) for 30 minutes and diaminobenzidine-peroxidase substrate for five minutes. Finally, the nuclei were lightly counterstained with haematoxylin and the tissues were dehydrated and mounted.

\section{SYNOVIAL VASCULARITY}

Using the anti-FVIII RAg stained specimens, we measured synovial vascularity by counting the number of vessels per square millimetre. To standardise the assessment and to avoid going too deeply into the subsynovial tissue where there are fewer inflammatory cells, only vessels within $150 \mu \mathrm{m}$ of the synovial surface were counted. A minimum length of $450 \mu \mathrm{m}$ along the synovial lining layer was examined in each sample.

\section{MORPHOMETRIC ANALYSIS}

The number of synovial samples containing vessels similar to high endothelial venules was recorded by two independent observers (OF and MS). In addition, using a Kontron image analysis system, an index of the tendency of the vessel to appear morphologically similar to high endothelial venules vessels (high endothelial venules index) was established. The peripheral limit of the vessel was defined by the limit of the anti-FVIII RAg staining (approximately the basement membrane). By calculating the area contained by the outer vessel limit (area 1) (fig 1), and subtracting from it the area contained by the vessel lumen (area 2), the difference obtained is proportional to the height of the endothelial cells. The high endothelial venules index is therefore defined as $\Sigma$ (area 1 -area $2) / n$, where $n$ is the number of vessels examined. In each specimen recorded $\mathbf{n}$ was greater than or equal to eight. The high endothelial venules index was calculated by two independent observers, one of whom was unaware of the source of the specimen.

\section{STATISTICAL ANALYSIS}

Differences between groups were examined with a Mann-Whitney U test.

\section{Results}

In non-inflamed synovium tissues, blood vessels were readily identified in sections stained with haematoxylin and eosin. In inflamed synovium tissues, however, it was often difficult to identify blood vessels when they were surrounded by a cellular infiltrate (fig 2A). By staining the 
specimens with anti-FVIII RAg, blood vessels could be more easily distinguished from the surrounding cells (fig 2B). Anti-FVIII RAg appeared to be both a sensitive and specific marker for vascular endothelial cells in all of the specimens studied.

\section{SYNOVIAL VASCULAR PROLIFERATION}

The number of vessels per square millimetre was calculated for each biopsy specimen and the results are presented in fig 3 . The mean (SD) value in synovial biopsy samples obtained from patients with clinically inflamed knee joints (group A) was 390 (90). In contrast, the mean number of vessels per square millimetre in synovium tissue obtained from the four patients with apparently unaffected knee joints (group B) was only 280 (30), similar to the value of 270 (30) found in synovial tissues from the control subjects (group $\mathrm{C})(\mathrm{p}<0 \cdot 01, \mathrm{~A} v \mathrm{C})$.

\section{MORPHOMETRIC ANALYSIS}

The presence of vessels similar to high endothelial venules in synovial membrane sections obtained from the three groups was recorded by two independent observers. The results obtained by both observers were similar. Figure 4 shows

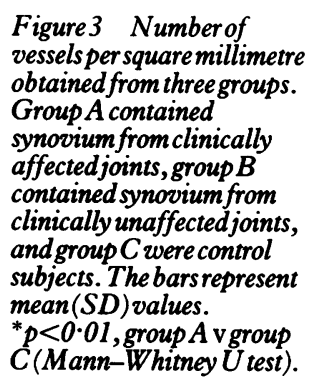

Figure 3 Numberof vesselsper square millimetre obtained from three groups. Group A contained synovium from clinically affected joints, group $B$ contained synovium from clinically unaffected joints, and group $C$ were control subjects. The bars represent mean $(S D)$ values.

$* p<0.01$, group $A$ v group C(Mann-Whitney Utest $)$

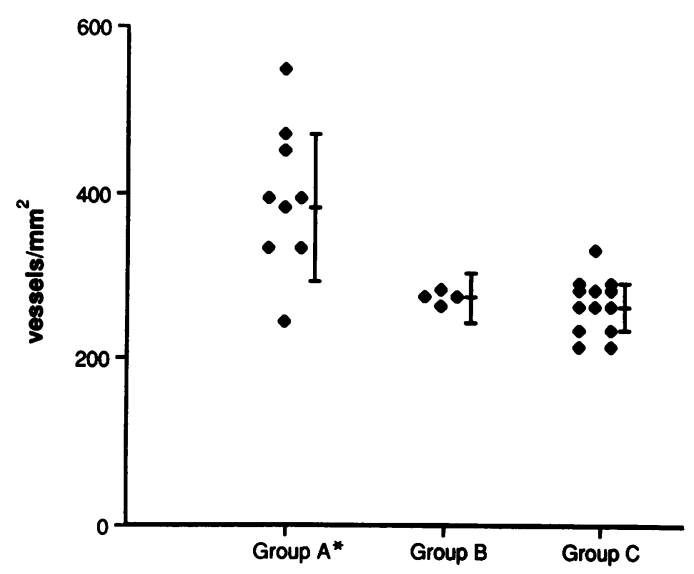

Figure 4 Tissuestained with anti-factor VIII related antigen. Thissection wasobtained from a clinically affectedjoint (group A). Arrowindicates a vessel similar to high endothelialvenules.

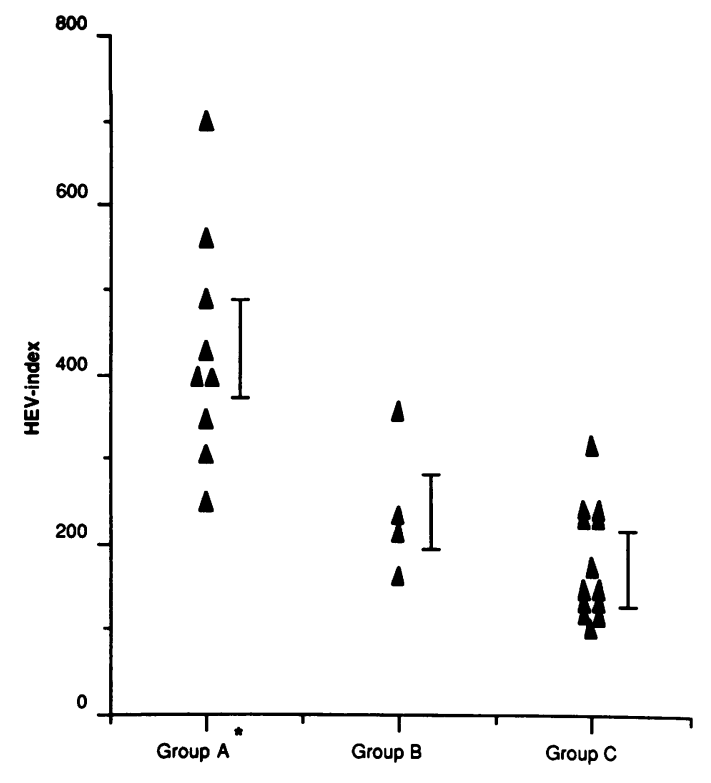

Figure 5 Highendothelial venules $(H E V)$ index. Synovium was obtained from three groups as outlined in fig 3. The bars represent mean (SEM) values. ${ }^{*} p<0.01$, group A v C (Mann-Whitney U test $)$

a typical vessel similar to high endothelial venules with tall endothelial cells protruding into the vessel lumen. Vessels similar to high endothelial venules were identified in seven of nine samples in group A patients. None was seen in either group B or C. These results were further supported by calculation of the high endothelial venules index. As shown in fig 5 , the mean (SEM) high endothelial venules index in group A was 430 (58) and this was greater than the values seen in group $B(242(41))$ and group $\mathrm{C}(181(41))(\mathrm{p}<0 \cdot 01, \mathrm{~A} v \mathrm{C})$.

\section{Discussion}

The blood vessels in synovial membrane biospy specimens obtained from two groups of patients with rheumatoid arthritis were examined for evidence of proliferation and altered endothelial morphology. These observations are of interest in the context of other features seen in synovial membrane tissues obtained from clinically unaffected rheumatoid joints. ${ }^{16}$ The most common change was hyperplasia of the synovial lining layer, which was seen in about two thirds of the biopsy samples. A mononuclear cell infiltrate, usually sparse, was seen in only one third of the samples. These results show that tissues obtained from patients with clinical and histological knee joint synovitis were characterised by prominent vascular proliferation and the number of vessels per square millimetre associated with overt synovitis was significantly greater than control values. In contrast, the number of vessels per square millimetre seen in synovial tissues obtained from unaffected knee joints of patients with rheumatoid arthritis was similar to the control samples, suggesting that clinical synovitis may evolve as vascular proliferation advances. A characteristic change in endothelial morphology with prominent vessels similar to high endothelial venules was only seen in patients with clinical synovitis. 
There is considerable evidence suggesting that the cells occupying the thickened lining layer are predominantly mononuclear phagocytic cells which migrate from the postcapillary venules of the sublining layer. ${ }^{18-20}$ These mononuclear phagocytic cells are characterised by the presence on their surface of adhesion molecules associated with diapedesis. It has been suggested that these cells might be responding to a chemotactic stimulus arising within the joint space. ${ }^{21}$ Thus the finding in this study of thickening of the lining layer in the absence of clinical synovitis suggests that the accumulation of mononuclear phagocytic cells at the joint surface does not primarily depend on changes in endothelial function and morphology.

The rheumatoid arthritis synovium is infiltrated by a variety of mononuclear cells, of which $\mathrm{T}$ lymphocytes predominate. $^{22} \mathrm{~T}$ and $\mathrm{B}$ lymphocytes pass through the synovial venules to form lymphocyte-rich perivascular infiltrate $^{23}$ containing T helper cells and HLA-DR mononuclear cells. ${ }^{24-29} \mathrm{~T}$ cells may migrate through the synovium and occupy transitional areas, ${ }^{30}$ which also contain a variety of other cell populations, including indigitating dendritic cells, macrophages, plasma cells, and fibroblasts. ${ }^{6}$ The role of the endothelial cell in the migration of mononuclear cells to inflammatory sites has recently been studied intensively. The cytokine mediated adherence of lymphocytes to the vascular endothelium is the first step in their passage from the circulation into the foci of inflammation. ${ }^{15}$ 31-34 The endothelial cells may function in lymphocyte migration as accessory cells in lymphocyte activation ${ }^{35}$ through their ability to present antigen to $T$ cells $^{36}$ or by secreting cytokines. ${ }^{37}{ }^{38}$ In addition, endothelial cells in the rheumatoid synovium have been shown to express adhesion molecules which recognise and bind to similar adhesion molecules on lymphocytes. ${ }^{39} 40$ Although the intracellular adhesion molecule 1 (ICAM-1) and the lymphocyte function associated antigen 3 (LFA-3) are expressed in the rheumatoid synovium, ${ }^{39}$ a distinct endothelial recognition system that controls lymphocyte traffic into the inflamed synovium has been suggested..$^{40}$

Increased angiogenesis and morphological changes in endothelial cells seem to represent a critical stage in the evolution and progression of chronic synovitis. Although perivascular lymphocytes do accumulate in its absence, the number and percentage of lymphocytes are thought to be dependent on endothelial tallness. ${ }^{6}$ The exact mechanism of this vascular change is not understood, but cytokines including interleukin 1, tumour necrosis factor, and immune interferon have been implicated. ${ }^{41-43}$ Several recent studies have elucidated some of the events which follow the migration of $T$ cells from the circulation into the synovium. Naive $T$ cells accumulate in the perivascular areas before maturation, activation, and further migration. ${ }^{44}$ As thickening of the lining layer and mononuclear cell infiltration seem to take place in the absence of clinical synovitis, there may be a critical level of activation or concentration of cytokines necessary to induce the required vascular morphological changes or to increase the expression of endothelial adhesion molecules.

This study was supported by grants from the Health Research Board of Ireland and the Arthritis Foundation of Ireland. The authors are grateful to Pauline Curran for preparing the manuscript.

1 Sokoloff L, Hough A J. Pathology of rheumatoid arthritis and allied disorders. In: McCarty DJ, ed. Arthritis and allied conditions. Philadelphia: Lea and Febiger, 1985 571-92.

2 Brown R A, Weiss J B, Tomlinson I W, Phillips P, Kumar S. Angiogenic factor from synovial fluid resembling that from tumours. Lancet 1980; i: 682-5.

3 Vraeko $R$. Basal lamina layering in diabetes mellitus: evidence for accelerated rate of cell death and regeneration. Diabetes 1974; 23: 94-104.

4 Ausprunk D H, Folkman J. Migration and proliferation of endothelial cells in preformed and newly formed blood vessels during tumour angiogenesis. Microvasc Res 1977; 14: 53-65.

5 Freemont A J, Jones C J P, Bromley M, Andrews P. Changes in vascular endothelium related to lymphocyte collections in diseased synovia. Arthritis Rheum 1983; 26: 1427-33.

6 Iguchi T, Ziff M. Electron microscopic study of rheumatoid synovial vasculature: intimate relationship between tal endothelium and lymphoid aggregation. $\mathcal{F}$ Clin Invest 1986 77: $355-61$.

7 Matsubara T, Ziff M. Basement thickening of postcapillary venules and capillaries in rheumatoid synovium. Immunoelectron microscopic and electron microscopic morphometric analysis. Arthritis Rheum 1987; 30: 18-30.

8 Schoefl G I. The migration of lymphocytes across the vascular endothelium in lymphoid tissue. F Exp Med 1972; 136: 568-88.

9 Anderson A O, Anderson N D. Lymphocyte emigration from high endothelial venules in rat lymph nodes. Immunology 1976; 31: 731-48.

10 Nightingale G, Hurley J V. Relationship between lymphocyte emigration and vascular endothelium in chronic inflammation. Pathology 1978; 10: 27-44.

11 Harlan J M. Leukocyte-endothelial interactions. Blood 1985 65: 513-25.

12 Parrott D V, de Souza M A, East J. Thymus-dependent areas in the lymphoid organs of neonatally thymectomized mice. 7 Exp Med 1966; 123: 191-204.

13 Pober J A, Gimbrone M A, Cotran R S, et al. Ia expression by vascular endothelium is inducible by activated $T$ cells and by human interferon. $\mathcal{F}$ Exp Med 1983; 157: 1339-53.

14 Fitzgerald O M, Hess E V, Chance A, Highsmith R F Quantitative studies of human monokine-induced endotheQuantitative studies of human monokine-induced endo
lial cell elongation. F Leukocyte Biol 1987; 41: 421-8.

15 Yu C-L, Haskard D O, Cavender D E, Johnson A R, Ziff M. Human gamma interferon increases the binding of $T$ lymphocytes to endothelial cells. Clin Exp Immunol 1985; 62: $554-60$.

16 Soden M, Rooney M, Cullen A, Whelan A, Feighery C, Bresnihan B. Immunohistologic features in the synovium obtained from clinically uninvolved knee joints of patients with rheumatoid arthritis. $B r \mathcal{J}$ Rheumatol 1989; 28: 287-92.

17 Ropes M W, Bennett G A, Cobb S, Jacox R, Jessar R A. 1958 revision of diagnostic criteria for rheumatoid arthritis. Bull Rheum Dis 1958; 9: 175-6.

18 Edwards J C W. The origin of type A synovial lining cells. Immunology 1982; 161: 227-31.

Immunology 1982; 161: 227-31.
19 Henderson B, Pettipher E R. The synovial lining cell: biology Henderson B, Pettipher E R. The synovial lining cell: bio
and pathology. Semin Arthritis Rheum 1985; 15: 1-32.

20 Lalor P A, Mapp P I, Hall P A, Revell P A. Proliferative activity of cells in the synovium, as demonstrated by a monoclonal antibody, K167. Rheumatol Int 1987; 7: 183-6

21 Allen C A, Highton J, Palmer D G. Increased expression of p150, 95 and CR3 leukocyte adhesion molecules by mononuclear phagocytes in rheumatoid synovial membranes. Comparison with osteoarthritis and normal synovia membranes. Arthritis Rheum 1989; 32: 947-54.

22 Van Boxel J A, Paget S A. Predominantly T cell infiltrate in rheumatoid synovial membranes. $N$ Engl f Med 1975; 293: 517-20.

23 Ishikawa $\mathbf{H}$, Ziff $\mathbf{M}$. Electron microscopic observations of immunoreactive cells in the rheumatoid synovial membrane. immunoreactive cells in the rheuma

24 Meijer C J L M, de Graaff-Reitsma C B, Lafeber G J M, Cats $A$. In situ localization of lymphocyte subsets in synovial membranes of patients with rheumatoid arthritis usin monoclonal antibodies. F Rheumatol 1982; 9: 359-65.

25 Klareskog L, Forsum U, Wigren A, Wigzell H. Relationships between HLA-DR-expressing cells and $T$ cells of different subsets in rheumatoid arthritis synovial tissue. Scand f Immunol 1982; 15: 501-7.

26 Young C L, Adamson T C III, Vaughan J H, Fox R I Immunohistologic characterization of synovial membrane lymphocytes in rheumatoid arthritis. Arthritis Rheum 1984; 27: 32-9.

27 Kottinen Y T, Reitamo S, Ranki A, Häyry P, Kankaanapää $U$, Wegelius $O$. Characterization of immuno-competent cells of rheumatoid synovium from tissue secretions and eluates. Arthritis Rherm 1981; 24: 71-9.9.

28 Klareskog L, Forsum U, Malmna S, Tjeinlund U K, 
Kabelitz D, Wigren A. Appearance of anti-HLR-DRreactive cells in normal and rheumatoid synovial tissue. Scand 7 Immunol 1981; 14: 183-92.

29 Førre 0 . Thoen J, Doblong J H, et al. Detection of $T$ lymphocyte subpopulations in the peripheral blood and lymphocyte subpopulations in the peripheral blood and synovium of patients with rheumatoid arthritis and juvenile rheumatoid arthritis using

30 Kurosaka M, Ziff M. Immunoelectron microscopic study of the distribution of $T$ cell subsets in rheumatoid synovium. $\mathcal{F} \operatorname{Exp}$ Med 1983; 158: 1191-210.

31 Cavender D E, Haskard D O, Joseph B, Ziff M. Interleukin I increases the binding of human $B$ and $T$ lymphocytes to endothelial cell monolayers. F Immunol 1986; 136: 203-7.

32 Yu C-L, Haskard D O, Cavender D, Ziff M. Effects of bacterial lipopolysaccharide on the binding of lymphocytes to endothelial cell monolayers. I Immunol 1986; 136: $569-73$.

33 Haskard D, Cavender D, Ziff M. Phorbolester-stimulated T lymphocytes show enhanced adhesion to human endothelial lymphocytes show enhanced adhesion to human

34 Oppenheimer-Marks N, Ziff M. Binding of normal human mononuclear cells to blood vessels in rheumatoid arthritis synovial membrane. Arthritis Rheum 1986; 29: 789-92.

35 Ashida E R, Johnson A R, Lipsky P E. Human endothelial cells-lymphocyte interaction. Endothelial cells function as accessory cells necessary for mitogen-induced human $T$ lymphocyte activation in vitro. $\mathcal{f}$ Clin Invest 1981; 67: $1490-9$.

36 Bruger D R, Ford D, Vetto R M, et al. Endothelial cell presentation of antigen to human T cells. Hum Immunol 1981; 3: 209-30.
37 Wagner C R, Vetto R M, Bruger D R. Expression of I-regionassociated antigen (Ia) and interleukin I by subcultured human endothelial cells. Cell Immunol 1985; 93: 91-104.

38 Stern D M, Bank I, Nawroth P P, et al. Self-regulation of procoagulant events on the endothelial cell surface. $\mathcal{J}$ Exp

39 Hale L P, Martin M E, McCollum D E, et al. Immunohistologic analysis of the distribution of cell adhesion molecules within the inflammatory synovial microenvironment. Arthritis Rheum 1989; 32: 22-30.

40 Jalkanen S, Steer A C, Fox R I, Butcher E C. A distinct endothelial cell recognition system that controls lymphocyte traffic into inflamed synovium. Science 1986; 233: 556-8.

41 Dumonde D C, Pulley M S, Paradinar F J, et al. Histologic features of skin reactions to human lymphoid cell line lymphokine in patients with advanced cancer. $\mathcal{F}$ Pathol 1982; 138: 289-308.

42 Fitzgerald $O$, Chance A, Highsmith R F, Hess E V. Interleukin-1 as a modulator of endothelial cell shape and function during the inflammation response. Arthritis Rheum 1987; 30: S82.

43 Stolpen A H, Guinan E C, Fiers W, Pober J S. Recombinant tumor necrosis factor and immune interferon act singly and in combination to reorganise human vascular endothelial cell monolayers. Am $\mathcal{Y}$ Pathol 1986; 123: 16-24.

44 Cush J J, Lipsky P E. Phenotypic analysis of synovial tissue and peripheral blood lymphocytes isolated from patients with rheumatoid arthritis. Arthritis Rheum 1988; 31: 1230-8.

45 Koch A E, Robinson P G, Radosevich J A, Pope R M. Immunophenotyping of rheumatoid synovial tissue lymphocytes. Arthritis Rheum 1989; 32: S59. 